\title{
RIZATRIPTAN BENZOATE LOADED NATURAL POLYSACCHARIDE BASED MICROSPHERES FOR NASAL DRUG DELIVERY SYSTEM
}

\author{
MEENAKSHI SHARMA*, NITIN SHARMA, ANJANA SHARMA
}

\author{
Department of Pharmacy, Meerut Institute of Engineering and Technology, NH-58, Baghpat Crossing, Partapur Bypass Road, Meerut, \\ 250005, India \\ Email: meenakshisharma500@gmail.com
}

Received: 10 Jun 2018, Revised and Accepted: 14 Aug 2018

\begin{abstract}
Objective: The objective of this research was to formulate and evaluate the different grades of rizatriptan benzoate loaded polysaccharide based microspheres for the nasal drug delivery system.

Methods: The polysaccharide was extracted from the seed of Trigonella foenum-graecum and microspheres were prepared by emulsification, followed by crosslinking using epichlorohydrin. A $3^{2}$ full factorial design was employed in formulating the microspheres with polymer concentration $\left(\mathrm{X}_{1}\right)$, and stirring rate $\left(\mathrm{X}_{2}\right)$ as independent variables and particle size $\left(\mathrm{Y}_{1}\right)$ and entrapment efficiency $\left(\mathrm{Y}_{2}\right)$ were dependent variables.

Results: The microspheres were discrete and free-flowing. The mean particle size $\left(\mathrm{Y}_{1}\right)$ of microspheres ranged from $40.82+12 \mu \mathrm{m}$ to $62.48+0.41$ $\mu \mathrm{m}$ and the encapsulation efficiency $\left(\mathrm{Y}_{2}\right)$ was found to be increased from $60.7+0.2 \%$ to $79.22+0.2 \%$ as the drug polysaccharide ratio increased. A $3^{2}$ full factorial design confirmed that the $X_{1}$ and $X_{2}$ both effect on particle size whereas $X_{1}$ alone effect on entrapment efficiency. SEM revealed the smooth spherical surface of microspheres whereas kinetic model revealed that drug release followed the case II transport. FTIR indicated good compatibility of the excipients with rizatriptan benzoate. Stability studies were carried out for formulation $\mathrm{F} 7$ at $4{ }^{\circ} \mathrm{C}$ ambient, $25+2^{\circ} \mathrm{C} / 60+5 \%$, $40+2^{\circ} \mathrm{C} / 75+5 \%$ relative humidity revealed that the physical drug appearance, entrapment efficiency were within the permissible limits.
\end{abstract}

Conclusion: The result obtained in this research work indicate a promising potential of control release rizatriptan benzoate loaded microspheres whereas the Trigonella foenum-graecum polysaccharide used as rate controlling polymer for the effective treatment of migraine patients.

Keywords: Rizatriptan benzoate, Polysaccharide, Microspheres, Nasal drug delivery.

(C) 2018 The Authors. Published by Innovare Academic Sciences Pvt Ltd. This is an open access article under the CC BY license (http://creativecommons.org/licenses/by/4.0/) DOI: http://dx.doi.org/10.22159/ijap.2018v10i5.27877

\section{INTRODUCTION}

In a novel drug delivery system, various route of administration may be used to achieve the controlled and targeted drug delivery [1]. A nasal cavity, as a site of drug delivery, have many advantages such as avoid first-pass metabolism, applicability for long-term treatment and because of the large surface area for absorption it may provide ease of administration. In a novel drug delivery system, microspheres are used to improve the bioavailability and stability of a drug. Intranasal drug administration is receiving increased attention as a delivery method for bypassing the blood-brain barrier (BBB) and rapidly targeting therapeutics to the central nervous system (CNS) [2]. There are two classes of nasal delivered therapeutics are in the market. The first one comprises with low molecular weight and hydrophobic drugs mostly useful in the treatment of the nasal mucosa and sinus. Whereas the second class of drugs having poor absorption properties, instability in a gastrointestinal tract (GIT) and have a sufficient nasal absorption to display systemic effects [3]. Single emulsion technique is a well-established process for microspheres preparation. The microparticulate carriers of natural polysaccharides i.e., those of proteins and carbohydrates are prepared by a single emulsion technique. The natural polymers are dissolved or dispersed in aqueous medium followed by dispersion in a non-aqueous medium like oil. In the next step, the cross-linking of the dispersed globule is carried out. The cross-linking can be achieved either by heat or by using the chemical crosslinkers [4].

Rizatriptan benzoate is a selective serotonin (5-hydroxytryptamine; 5HT) type 1B and 1D receptor agonist ("triptan") commonly used for the treatment of a migraine and completely absorbed from GIT, but absolute bioavailability (as conventional tablet) is $45 \%$, indicating the first-pass metabolism, which is due to the metabolism of the drug by monoamine oxidase A isoenzyme (MAO-A) to an inactive indole acetic acid metabolite. Rizatriptan benzoate has also relatively short elimination half-life (about $3 \mathrm{~h}$ ) and the prolonged drug release is needed $[5,6]$.

The aim of this research was, to formulate and evaluated rizatriptan benzoate loaded polysaccharide based microspheres for the delivery via the nasal route with aim to avoid hepatic first-pass metabolism, and enhance residence time. The natural polysaccharide was extracted from the seeds of Trigonella foenum-graecum L. (Fenugreek seeds, Family: Fabaceae) as mucoadhesive excipient [7]. In traditional Chinese medicine, it is also used for kidney problems and conditions affecting the male reproductive tract. The recent researches have proved it beneficial for atherosclerosis, constipation, diabetes, high cholesterol and hypertriglyceridemia [8].

\section{MATERIALS AND METHODS}

\section{Materials}

Rizatriptan benzoate was obtained as a generous gift from Cipla (Raighar, India). Castor oil, epichlorohydrin, Isopropyl alcohol and acetone were purchased from the $\mathrm{CDH}$, (New Delhi, India). All other reagents used were of analytical grade.

\section{Extraction of fenugreek polysaccharide}

Extraction of polysaccharide was done using a reported method [9, 10] with minored modification. The plant materials of Trigonella foenum-graecum (fenugreek seeds, NHCP/NBPGR/2014-16) were collected from the local market in Meerut (India), and were washed with water to remove dirt, dried and crushed them to convert into powdered form. The powder was soaked in water for 5-6 h, boiled for $30 \mathrm{~min}$. and allowed to stand for $1 \mathrm{hr}$ so that all the mucilage was released into the water. Then the materials were squeezed from muslin bag to remove the marc from the solution. After that $1500 \mathrm{ml}$ of acetone was added to the filtrate to precipitate the mucilage. The mucilage was separated, dried in an oven at a temperature less than $50{ }^{\circ} \mathrm{C}$, and the dried powder was passed through a sieve no. 80 and retained on sieve no. 100 . It was stored in desiccators.

\section{Preparation of microspheres by emulsion technique}

Microspheres of Trigonella foenum-graecum polysaccharides were prepared using an emulsification technique. Aqueous 
solutions containing different drug and polysaccharide ratios (1:1 to $1: 3$ ) were prepared by dissolving required amount of rizatriptan benzoate and polysaccharide in distilled water. The final volume was adjusted in such a way such a way that the concentration of the polysaccharide in the final solution was $2 \%$ $\mathrm{w} / \mathrm{v}$. The mixture was kept for $4 \mathrm{~h}$ under magnetic stirring at 100 rpm (round per minute) for completed hydration of polysaccharide. An aqueous phase was emulsified into castor oil using span $80(1 \% \mathrm{v} / \mathrm{v})$ as an emulsifying agent. The phase: volume ratio of the oil and aqueous phase was maintained at 10:1. The emulsion was homogenized for $5 \mathrm{~min}$. with the addition of $0.2 \mathrm{ml} \mathrm{H}_{2} \mathrm{SO}_{4}$ using high speed a mechanical stirrer (Yamato, LT400, Tokyo, Japan) at different rotation rate (2000 to $3000 \mathrm{rpm})$. Epichlorohydrin $(4 \% \mathrm{v} / \mathrm{v})$ was added for covalent crosslinking of droplets. Stirring was continued for $18 \mathrm{~h}$ at $40^{\circ} \mathrm{C}$. The formed microspheres were separated by sedimentation and centrifugation at $1500 \mathrm{rpm}$ for $5 \mathrm{~min}$. Microspheres were washed thrice using isopropyl alcohol [11].

\section{Experimental design}

The design of the experiment is an approach for effectively and efficient exploring the cause and effect relationship between process variables and output. A 2-factor 3-level factorial central composite experimental design technique was employed to investigate the variables. This technique was applied to quantify the influence of operating parameters on the particle size and entrapment efficiency of microspheres. The dependent variables were polymer concentration and stirring rate. The factorial design parameters and experimental condition are shown in table 1. Various batches of rizatriptan benzoate loaded microspheres were prepared based on the $3^{2}$ factorial designs. The independent variables were polymer concentration 1 to $3 \%\left(\mathrm{X}_{1}\right)$ and stirring rate 2000 to $3000 \mathrm{rpm}\left(\mathrm{X}_{2}\right)$ and their levels were shown in table 1.

Table 1: Factorial design parameters and experimental condition

\begin{tabular}{llll}
\hline S. No. & Coded value & Actual value & Stirring rate in rpm $\left(\mathbf{X}_{2}\right)$ \\
\cline { 3 - 4 } & & Drug-polysaccharide ratio $\left(\mathbf{X}_{\mathbf{1}}\right)$ & 2000 \\
\hline 1 & -1 & $1: 1$ & 2500 \\
2 & 0 & $1: 2$ & 3000 \\
\hline
\end{tabular}

\section{Optimization data analysis and model validation}

A nonlinear quadratic polynomial model was generated to more precisely evaluated effect of independent variables on dependent variables using Design Expert v10 software (Stat-Ease, Inc. Minneapolis, MN).

$$
Y_{i}=\beta_{0}+\beta_{1} X_{1}+\beta_{2} X_{2}+\beta_{3} X_{3}+\beta_{3} X_{1} X_{2}+\beta_{4} X_{1}{ }^{2}+\beta_{5} X_{2}{ }^{2} \ldots
$$

Where $Y_{i}$ is the level of response variable, $\beta_{i}\left(\beta_{1}, \beta_{2}, \beta_{3}, \beta_{4}\right.$ and $\left.\beta_{5}\right)$ is the regression coefficient; $X_{1}, X_{2}$ stands for the main effect; $X_{1} X_{2}$ is the interactions between the main effects, and $X_{1}, X_{2}$ are quadratic terms of the independent variables that are used to simulate the curvature of the designed sample space. The $\mathrm{X}_{1}$ and $\mathrm{X}_{2}$ were termed as codes for the concentration of polysaccharide and stirring rate.

The polynomial equation was used to draw conclusions after considering the magnitude of coefficients, and the mathematical sign it carries, i.e., positive or negative. A positive sign signifies a synergistic effect, whereas a negative sign stands for an antagonistic effect. In the model analysis, the responses: the particle size of the microsphere and entrapment efficiency of all model formulations were treated by Design Expert ${ }^{\circledR}$ software. The best fitting mathematical model was selected based on the comparisons of several statistical parameters including the coefficient of variation (CV), the multiple correlation coefficient $\left(\mathrm{R}^{2}\right)$, adjusted multiple correlation coefficient (adjusted $\mathrm{R}^{2}$ ), and the predicted residual sum of square (PRESS), provided by Design Expert® software. Level of significance was considered at $\mathrm{p}<0.05$. Three-dimensional response surface plots resulting from equations were obtained by the Design Expert $₫$ software [12].

\section{Characterization of microspheres}

\section{Production Yield}

The production yield of microspheres of various batches were calculated using the weight of final product after drying with respect to the initial total weight of the drug and polymer used for the preparation of microspheres [13].

$$
\text { Yield }(\%)=\frac{\text { Weight of microspheres }}{\text { Total expected weight of drug and polymer }} \times 100 \ldots \ldots \text {.... (2) }
$$

\section{Particle size analysis}

The geometric particle size of microspheres was measured using a phase contrast microscope (Radical Instruments, India). Suspension of microspheres was prepared in paraffin oil. Two or three drops of the suspension were transferred onto a glass slide and covered with a coverslip. The geometrical diameter of 300 microspheres of each batch was separately measured, and the average diameter was calculated [14].

\section{Entrapment efficiency}

For the estimation of encapsulation efficiency and drug content, accurately weighed a sample of microspheres $(20 \mathrm{mg})$ was dispersed in $20 \mathrm{ml}$ phosphate buffer ( $\mathrm{pH}$ 6.8). The dispersion was sonicated for $30 \mathrm{~min}$ and kept overnight for the complete erosion of microspheres. Then the sample was centrifuged (Remi), filtered and analyzed using a UV-visible spectrometer (Shimadzu 1700, Japan) at $225 \mathrm{~nm}$. After that encapsulation efficiency and drug content of microsphere were calculated by the following equation (3).

Encapsulation efficiency (\%)

$$
=\frac{\text { Actual amount of drug }}{\text { Theoretical amount of drug }} \times 100 \ldots
$$

\section{Fourier transforms infrared spectroscopy (FTIR) studies}

To determine any possible changes in the chemical nature of the drug during the preparation of microspheres, FTIR spectra of drug, polysaccharide, and the microspheres were recorded by using the FTIR spectrophotometer (Shimadzu, Kyoto, Japan) following the potassium bromide disc method.

\section{Scanning electron microscopy (SEM)}

The surface morphology of the microspheres was studied using SEM (Leo, 435 VP, Milpitas, CA). Microspheres were placed on an aluminum stub with double-sided adhesive tape and were subjected to gold sputtering before SEM analysis.

\section{In vitro drug release}

The in vitro release of the drug from the microspheres was studied using the modified dissolution method [15]. An accurately weighed amount of microspheres equivalent to $10 \mathrm{mg}$ of drug was suspended into $10 \mathrm{ml}$ of phosphate buffer (pH 6.8) in a beaker containing $0.1 \% \mathrm{v} / \mathrm{v}$ of Tween 80 . The microspheres were packed into a small pouch of filter paper, which was kept immersed in the dissolution medium.

The medium was maintained at $37+1^{\circ} \mathrm{C}$ and continuously stirred at $50 \mathrm{rpm}$ using a magnetic stirrer. Samples $(200 \mathrm{ml})$ were withdrawn at the time interval of $5 \mathrm{~min}$., diluted, filtered and centrifuged at $4000 \mathrm{rpm}$ for $15 \mathrm{~min}$. The supernatant was collected and estimated for the drug content using UV spectrophotometer at $225 \mathrm{~nm}$. Quantitative estimation of released drug was done using a calibration curve of the drug in a phosphate buffer of $\mathrm{pH} 6.8$ in the concentration range of $1-10 \mu \mathrm{g} / \mathrm{ml}$. 


\section{Drug release kinetics}

To study the release kinetics of rizatriptan benzoate from Trigonella foenum-graecum microspheres, dissolution data were fit according to Zero-order, First-order, Higuchi, and Korsmeyer-Peppas equations. Value of kinetic rate constant $(\mathrm{k})$, mucoadhesive microspheres of Trigonella foenum-graecum correlation coefficient $\left(r^{2}\right)$ and release exponent (n) were calculated to find out the best fit model. To investigate the drug release mechanism, the release data were fitted to model representation: Zero order (see equation 4) as cumulative amount of drug released vs. time, First order (see equation 5) as log cumulative percentage of drug remaining vs. time and Higuchi's model (see equation 6) as cumulative percentage of drug released vs. square root of time [12].

\section{Zero-order}

$$
\mathrm{C}=\mathrm{K}_{0} \mathrm{t} \ldots \ldots . .(4)
$$

Where $\mathrm{K}_{0}$ is the zero-order rate constant expressed in units of concentration/time and $t$ is the time in minutes. A graph of concentration $v s$. time would yield a straight line with a slope equal to $\mathrm{K}_{0}$ and intercept the origin of the axes.

\section{First order}

$$
\log C=\log C_{0}-K_{\square} / 2.303
$$

Where $\mathrm{C}_{0}$ is the initial concentration of $\mathrm{d}$ the rug, $\mathrm{K}$ is the first order constant and $t$ is the time.

\section{Higuchi model}

$$
Q_{t}=K_{t}^{1 / 2}
$$

Where $Q_{t}$ is the amount of drug release in time $t, K$ is the kinetic constant and $t$ is the time in minutes.

\section{Korsmeyer-peppas model}

A more stringent test was used to distinguish between the mechanisms of drug release. The release data were fitted to the Peppas exponential model as a cumulative log percentage of drug released vs. log time (equation 7). The release exponent $\mathrm{n}$ and $\mathrm{K}$ value were calculated through the slope of the straight line.

$$
\mathrm{M}_{\mathrm{t}} / \mathrm{M}_{\infty}=\mathrm{K}_{\mathrm{t}}^{\mathrm{n}}
$$

Where $M_{t}$ represents an amount of the released drug at time $t, M_{\infty}$ is the total amount of drug released after an infinite time, $\mathrm{K}$ is the diffusion characteristic of drug polysaccharide system constant and $n$ is an exponent that characterizes the mechanism of drug release. The value of $\mathrm{n}$ indicates the drug release mechanism from the delivery system. If the exponent $\mathrm{n}=0.43$ then the drug release mechanism is Fickian diffusion, if $0.43<\mathrm{n}<0.85$ then it is non-Fickian or anomalous diffusion, if $\mathrm{n}=0.85$ mechanism is non-Fickian case II diffusion $[16,17]$.

\section{Stability studies}

Stability study was carried out for rizatriptan benzoate loaded microspheres as per ICH guidelines. The best batch of microspheres was sealed in an ambered coloured bottle and stored at $25+2^{\circ} \mathrm{C} / 60+5 \%$, $40+2^{\circ} \mathrm{C} / 75+5 \%$ relative humidity $(\mathrm{RH})$ for $90 \mathrm{~d}$. The sample was evaluated for physical appearance and entrapment efficiency [22].

\section{RESULTS AND DISCUSSION}

\section{Formulation of microspheres}

Nine formulations of rizatriptan benzoate loaded mucoadhesive microspheres were prepared by emulsion technique using factorial design, in which the independent variables of drug polysaccharide ratio 1 to $3 \%\left(\mathrm{X}_{1}\right)$ and stirring rate $\left(\mathrm{X}_{2}\right) 2000$ to $3000 \mathrm{rpm}$ and particle size $\left(\mathrm{Y}_{1}\right)$ and \% entrapment efficiency $\left(\mathrm{Y}_{2}\right)$ were taken a response parameters as the dependent variables as shown in table 2 .

Table 2: Formulation of microspheres using $3^{2}$ factorial designs

\begin{tabular}{lllll}
\hline Batch code & $\begin{array}{l}\text { Drug polysaccharide } \\
\text { ratio }\left(\mathbf{X}_{\mathbf{1}}\right)\end{array}$ & $\begin{array}{l}\text { Stirring rate } \\
\text { in rpm }\left(\mathbf{X}_{2}\right)\end{array}$ & $\begin{array}{l}\text { Particle size }(\boldsymbol{\mu m + S D})^{\mathrm{a}} \\
\left(\mathbf{Y}_{\mathbf{1}}\right)\end{array}$ & $\begin{array}{l}\text { Entrapment efficiency (\%+SD) } \\
\left(\mathbf{Y}_{2}\right)\end{array}$ \\
\hline $\mathrm{F}_{1}$ & -1 & -1 & $40.82+0.12$ & $60.70+0.20$ \\
$\mathrm{~F}_{2}$ & -1 & 0 & $55.82+0.50$ & $62.60+0.10$ \\
$\mathrm{~F}_{3}$ & -1 & +1 & $62.48+0.41$ & $65.07+1.30$ \\
$\mathrm{~F}_{4}$ & 0 & -1 & $49.15+1.02$ & $67.46+0.50$ \\
$\mathrm{~F}_{5}$ & 0 & 0 & $49.15+0.70$ & $68.66+0.41$ \\
$\mathrm{~F}_{6}$ & 0 & +1 & $49.98+1.20$ & $69.64+0.8$ \\
$\mathrm{~F}_{7}$ & +1 & -1 & $60.81+0.50$ & $70.84+1.2$ \\
$\mathrm{~F}_{8}$ & +1 & 0 & $57.48+0.80$ & $76.83+0.3$ \\
$\mathrm{~F}_{9}$ & +1 & +1 & $46.65+0.20$ & $79.22+0.2$ \\
\hline
\end{tabular}

${ }^{a}$ mean $+\mathrm{SD},(\mathrm{n}=3), \mathrm{n}=$ number of observation, $\mathrm{F}=$ formulation code of microspheres

\section{Optimization data analysis and model-validation}

\section{Fitting of data to the model}

The two factors with lower, middle and upper design points in coded and encoded values are shown in table 1 . The ranges of responses $Y_{1}$ and $Y_{2}$ were $40.82+0.12-62.48+0.41 \mu \mathrm{m}$ and $60.70+0.2-79.22+0.2 \%$, respectively. Response observed for all the prepared batches were fitted to various models using DesignExpert ${ }^{\circledR}$ software. It was observed that the best-fitted models were F1 for particle size and linear for entrapment efficiency. The values of $\mathrm{R}^{2}$, adjusted $\mathrm{R}^{2}$, predicted $\mathrm{R}^{2}, \mathrm{SD}$ and $\% \mathrm{CV}$ are given in table 3 .

The result of ANOVA in table 4 for the dependent variables demonstrates that the model was significant for both the response variables. It was observed that independent variables drug polysaccharide ratio $\left(\mathrm{X}_{1}\right)$ and stirring rate $\left(\mathrm{X}_{2}\right)$ had a positive effect on particle size $\left(\mathrm{Y}_{1}\right)$ and entrapment efficiency $\left(\mathrm{Y}_{2}\right)$.

Table 3: Summary of results of regression analysis for response $Y_{1}$ and $Y_{2}$

\begin{tabular}{lllll}
\hline Models & $\mathbf{R}^{\mathbf{2}}$ & Adjusted R & Predicted R & \\
\hline $\begin{array}{l}\text { Response }\left(\mathrm{Y}_{1}\right) \\
\text { F1 model }\end{array}$ & 0.8368 & 0.7388 & 0.6801 & \\
$\begin{array}{l}\text { Response }\left(\mathrm{Y}_{2}\right) \\
\text { Linear model }\end{array}$ & 0.9567 & 0.9422 & & \\
& & & 0.883 & \\
\hline
\end{tabular}


Table 4: Results of analysis of variance for a measured response

\begin{tabular}{llllll}
\hline Parameters & SS & DF & MS & F & Significance p \\
\hline Particle size & & & & & 0.0206 significant \\
Model & 337.98 & 3 & 112.66 & - & - \\
Residual & 65.94 & 5 & 13.19 & - & - \\
Total & 403.92 & 8 & - & 6.0001 significant \\
E. E. & & & & - \\
Model & 284.45 & 2 & 142.22 & - & - \\
Residual & 12.89 & 6 & 2.15 & - & \\
Total & 297.33 & 8 & - & & \\
\hline
\end{tabular}

\section{Regression equation}

Particle size $\left(\mathrm{Y}_{1}\right)=11.94+18.88 \mathrm{X}_{1}+19.29 \mathrm{X}_{2}-8.95 \mathrm{X}_{1} \mathrm{X}_{2} \ldots \ldots \ldots . . .(8)$
Entrapment efficiency $\left(\mathrm{Y}_{2}\right)=51.18+6.42 \mathrm{X}_{1}+2.48 \mathrm{X}_{2} \ldots \ldots \ldots \ldots \ldots \ldots . . . .$.

From the above equation 8 it was confirmed that the major factor which is influencing the particle size of the film is stirring rate $\left(\mathrm{X}_{2}\right)$. The interaction factor between both the independent variables is very less. The concentration of Trigonella foenum-graecum $\left(\mathrm{X}_{1}\right)$ also has an effect on particle size of Trigonella foenum-graecum microsphere. In case of entrapment efficiency, the concentration of Trigonella foenum-graecum $\left(\mathrm{X}_{1}\right)$ also has an effect on entrapment efficiency of microsphere because the higher the amount of polysaccharide, the more will be entrapment efficiency because of the more availability of polysaccharide to encapsulate the drug.

Polynomial quadratic models were generated for each response parameter, and the regression coefficients for each term regression model were summarized in table 5 together with $\mathrm{r}^{2}, \mathrm{~F}$ values (with $\mathrm{p}$ values) of the regression model. In the present study, the model was significant in all the cases because for all the dependent variables, the $\mathrm{p}$ value for the generated model was less than 0.05 . Effects of formulation variables on different dependent variables were assessed by this generated regression coefficient and $r^{2}$ values. The high values of correlation coefficients for all the response variables indicate a good fit (i.e., good agreement between the dependent and independent variables).

Table 5: Regression coefficient and $\mathbf{r}^{2}$ values for Trigonellafoenum-graecum microspheres containing rizatriptan benzoate

\begin{tabular}{|c|c|c|c|c|c|c|}
\hline Regression coefficient & $\beta_{0}$ & $\beta_{1}$ & $\beta_{2}$ & $\beta_{3}$ & & F-values for the model (p-value) \\
\hline Independent variables & & $\mathbf{X}_{1}$ & $\mathbf{X}_{2}$ & $\mathbf{X}_{1} \mathbf{X}_{2}$ & $\mathbf{r}^{2}$ & \\
\hline \multicolumn{7}{|l|}{ Dependent variables } \\
\hline Particle size & 11.94 & 18.88 & 19.29 & -8.95 & 0.8368 & $8.54(0.0206)$ \\
\hline Entrapment efficiency & 51.18 & 6.42 & 2.48 & 0 & 0.9567 & $66.23(<0.0001)$ \\
\hline
\end{tabular}

\section{Response surface plot analysis}

Three-dimensional response surface plots generated by the Design Expert ${ }^{\circledR}$ software are presented (in fig. 1 and 2) for the studied responses, i.e., particle size and entrapment efficiency. The (fig. 1) depicts response surface plot of drug polysaccharide ratio $\left(\mathrm{X}_{1}\right)$ and stirring rate $\left(\mathrm{X}_{2}\right)$ on particle size, which indicate that $\mathrm{X}_{1}$ and $\mathrm{X}_{2}$ show linear effect i.e., when increased polysaccharide concentration and stirring rate from 2000 to 3000 the value of particle size was decreased. The (fig. 2) represent response surface plot of the effect of drug polysaccharide ratio $\left(\mathrm{X}_{1}\right)$ and stirring rate $\left(\mathrm{X}_{2}\right)$ on entrapment efficiency which indicate a linear effect. This explains that the higher the amount of polysaccharide, the more will be entrapment efficiency because of the more availability of polysaccharide to encapsulate the drug.

\section{Optimization and validation}

The result in table 6 illustrates the comparison between the observed values of both the response $Y_{1}$ and $Y_{2}$ for all the batches were presented. It can be seen that in all cases there was a reasonable agreement between the experimental values. The equations describe the influence of the selected independent variables on the responses under study adequately. This indicates that the optimization technique was appropriated for optimizing the rizatriptan benzoate loaded Trigonella foenumgraecum microsphere. The low magnitudes of error in the present investigation prove the high prognostic ability of the optimization technique by factorial design.

Fig. 1: Response surface plots for the $X_{1}$ and $X_{2}$ on particle size $\left(Y_{1}\right)$, where $X_{1}=$ drug polysaccharide ratio, $X_{2}=$ stirring rate 
Fig. 2: Response surface plots for the $X_{1}$ and $X_{2}$ on entrapment efficiency $\left(Y_{2}\right)$, where $X_{1}=$ drug polysaccharide ratio and $X_{2}=$ stirring rate

Table 6: The predicted and observed response variables of the rizatriptan benzoate loaded microspheres

\begin{tabular}{|c|c|c|c|c|c|c|}
\hline \multirow[t]{3}{*}{ Formulation code } & \multicolumn{6}{|c|}{ Actual and predicted values for } \\
\hline & \multicolumn{3}{|c|}{ Particle size (Y $\left.\mathrm{Y}_{1}\right)$} & \multicolumn{3}{|c|}{ Entrapment efficiency $\left(\mathrm{Y}_{2}\right)$} \\
\hline & Actual value & Predicted value & Residual & Actual value & Predicted value & Residual \\
\hline F1 & 40.82 & 41.16 & -0.34 & 60.70 & 60.08 & 0.62 \\
\hline $\mathrm{F} 2$ & 55.82 & 51.50 & 4.32 & 62.60 & 62.56 & 0.04 \\
\hline F3 & 62.48 & 61.84 & 0.64 & 65.07 & 65.04 & 0.03 \\
\hline $\mathrm{F} 4$ & 49.15 & 51.09 & -1.94 & 67.46 & 66.50 & 0.96 \\
\hline F5 & 49.15 & 52.48 & -3.33 & 68.66 & 68.98 & -0.32 \\
\hline F6 & 49.98 & 53.87 & -3.89 & 69.64 & 71.46 & -1.82 \\
\hline F7 & 60.81 & 61.02 & -0.21 & 70.84 & 72.92 & -2.08 \\
\hline F8 & 57.48 & 53.46 & 4.02 & 76.83 & 75.40 & 1.43 \\
\hline F9 & 46.65 & 45.90 & 0.75 & 79.22 & 77.88 & 1.34 \\
\hline
\end{tabular}

$\mathrm{F}=$ formulation code of microspheres

\section{Characterization of microspheres}

\section{Percentage yield}

The percentage yield of production was found in the range $64.5+0.2 \%$ to $77.60+0.6 \%$ (table 7 ). These respectively low values could be attributed mainly to the loss of fines particles during the washing of microspheres with Isopropyl alcohol.

\section{Particle size}

The mean particle size of microspheres ranged from $40.82+10 \mu \mathrm{m}$ to $62.48+6.56 \mu \mathrm{m}$ (table 7 ), indicating a narrow size distribution (fig. 1). Such a particle size distributions were considered favorable for intranasal administration. The particle size of microsphere was to increase with an increase in the drug polysaccharide ratio. The formation of larger droplets during emulsification due to the higher viscosity of polysaccharide solution at higher concentration. Increase stirring rate also contributed to decreasing the particle size but not much significantly and this may be due to the narrower range being selected to focus this parameter [20].

\section{Encapsulation efficiency result}

The percentage encapsulation efficiency was found to increase as the drug polysaccharide ratio increased (table 7). It was $60.7+0.2 \%$ in a batch F1 (1:1 drug polysaccharide ratio) and increased subsequently, to $79.22+0.22 \%$ in a batch F9 (1:3 drug polysaccharide ratio). The reason behind the increased value of percent encapsulation efficiency is the more availability of Trigonella foenum-graecum polysaccharide as a carrier for the encapsulation of drug. At high concentration of polysaccharide, highly viscous aqueous droplets are formed during emulsification, which makes a complex network of polysaccharide and prevents the migration of drug into surrounding media [21]. In a batch F1 with drug polysaccharide ratio 1:1, drug loading was less because most of the drug remained unentrapped due to an insufficient amount of carrier polysaccharide.

Table 7: Mean value of percentage yield, particle size and entrapment efficiency of microspheres

\begin{tabular}{llll}
\hline Batch code & Percentage yield $^{\mathbf{a}}(\boldsymbol{\%}+\mathbf{S D})$ & Particle size $^{\mathbf{a}}(\boldsymbol{\mu m}+\mathbf{S D})$ & Entrapment efficiency $^{\mathbf{a}} \boldsymbol{( \% + S D )}$ \\
\hline F1 & $64.5+0.2$ & $40.82+0.12$ & $60.70+0.20$ \\
F2 & $70.4+0.5$ & $55.82+0.50$ & $62.60+0.10$ \\
F3 & $76.2+0.1$ & $62.48+0.41$ & $65.07+1.30$ \\
F4 & $74.5+0.2$ & $49.15+1.02$ & $67.46+0.50$ \\
F5 & $69.7+1.3$ & $49.15+0.70$ & $68.66+0.41$ \\
F6 & $72.3+0.1$ & $49.98+1.20$ & $69.64+0.8$ \\
F7 & $77.6+0.6$ & $60.81+0.50$ & $70.84+1.2$ \\
F8 & $71.4+1.4$ & $57.48+0.80$ & $76.83+0.3$ \\
F9 & $73.1+0.2$ & $46.65+0.20$ & $79.22+0.2$ \\
\hline
\end{tabular}

amean+SD $(n=3), n=$ no of observation, $F=$ formulation code of microspheres 


\section{FTIR spectroscopy}

Interpretation of FTIR spectrum of Trigonella foenum-graecum polysaccharide (fig. 3(a)) was:--OH stretch (3656.78),-C-H (3150.50),$\mathrm{C}=\mathrm{C}(2313.46),-\mathrm{C}-\mathrm{H}$ bend (1636.49), $\mathrm{C}-\mathrm{H}$ rock (1617.20), $-\mathrm{CH}$ bend out of plane (1029.45) and FTIR spectrum of rizatriptan benzoate (fig. 3(b)) was-NH stretching (3446), $-\mathrm{CH}_{3}$ stretching (2947), $-\mathrm{CH}_{2}$ stretching (2893), $-\mathrm{C}=\mathrm{C}$ stretching (1608), $-\mathrm{C}=\mathrm{N}$ stretching (1506), $-\mathrm{NH}$ bending (1570), $-\mathrm{CH}_{2}$ bending (1458), $-\mathrm{CH}_{3}$ bending (1375),- $\mathrm{CN}$ $(1016,1140,1296)$.

The spectrum of physical mixture indicates that there was no evidence of any possible interaction between the drug and the polysaccharide and characteristic peaks of the pure drug were found present in the spectrum of mixture (fig. 3 (c)), which confirmed the absence of interaction between a drug and the polysaccharide $[10,18-19]$.

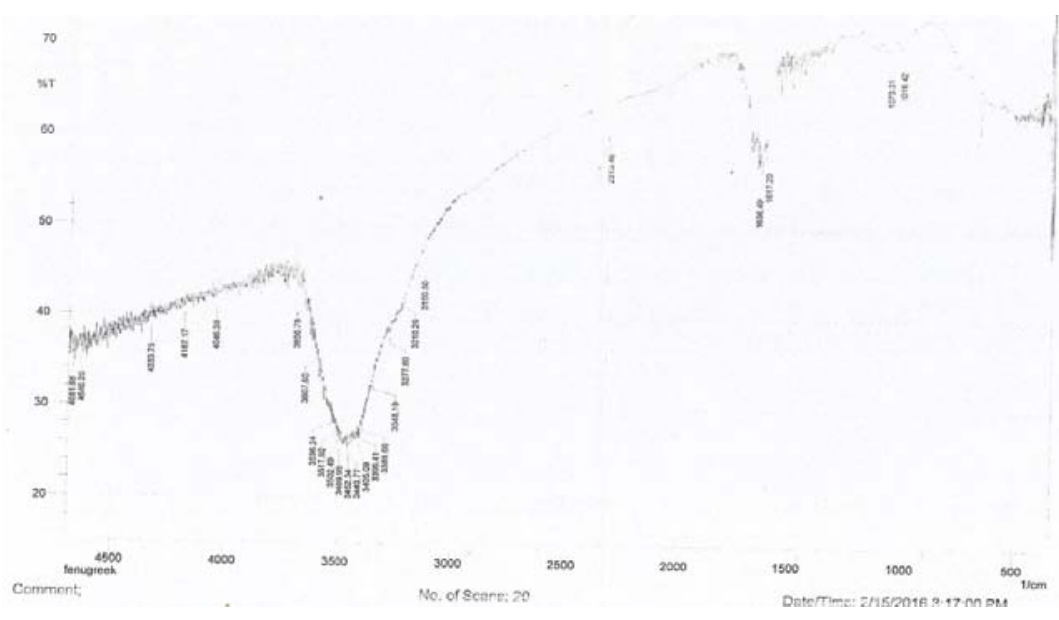

(a)

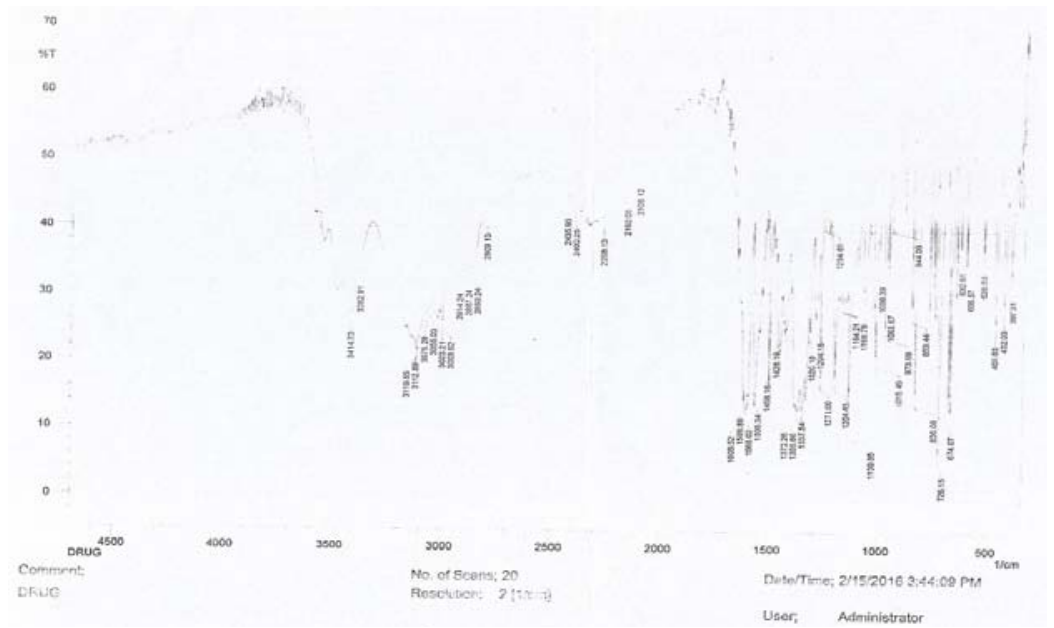

(b)

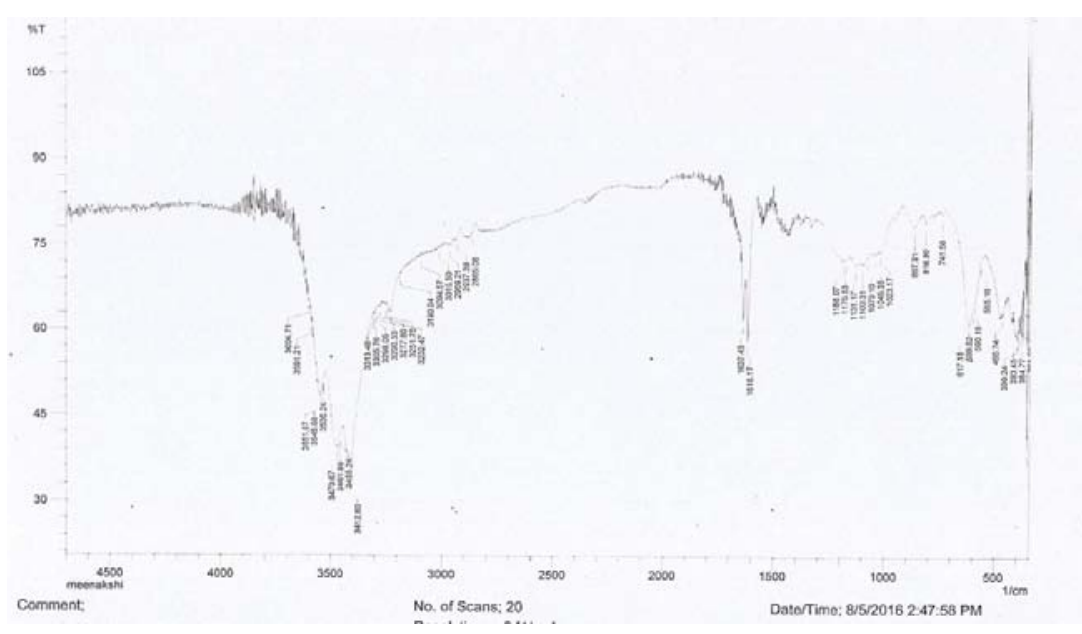

(c)

Fig. 3: IR spectra of Trigonella foenum-graecum polysaccharide (a), Rizatriptan benzoate (b) and Physical mixture (Rizatriptan benzoate and Trigonella foenum-graecum polysaccharide) (c) 


\section{Surface morphology}

The morphology of all the batches was examined by a Scanning Electron Microscopy (SEM) shown in fig. 4. Microspheres are spherical and possessed a smooth surface also they had no rupture on the surface; such morphology would result in slow clearance and good deposition pattern in a nasal cavity [16].

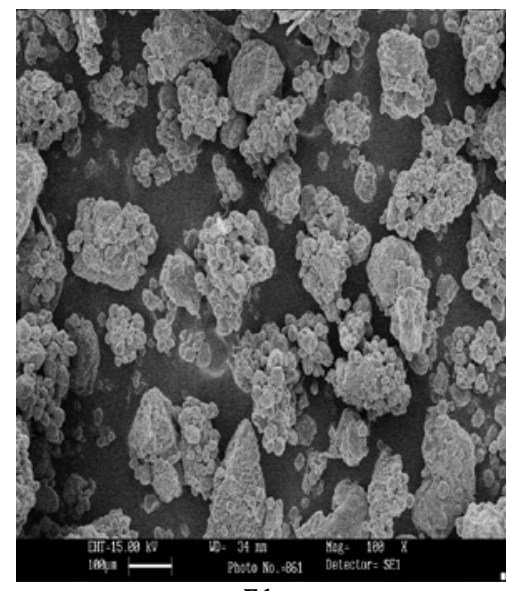

F1

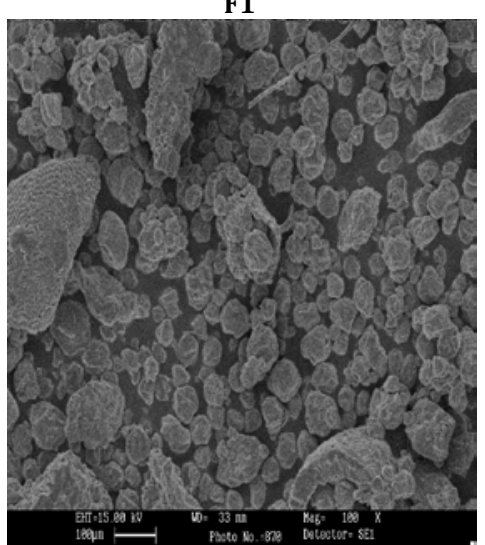

F4

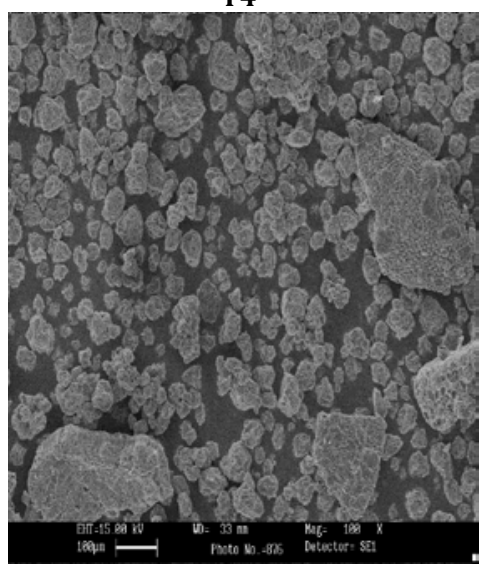

F7

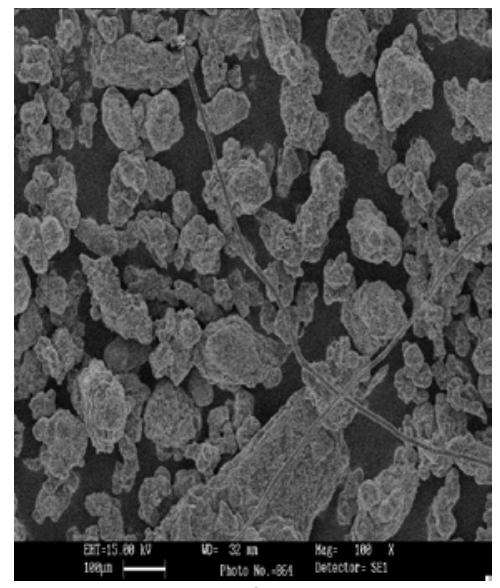

F2

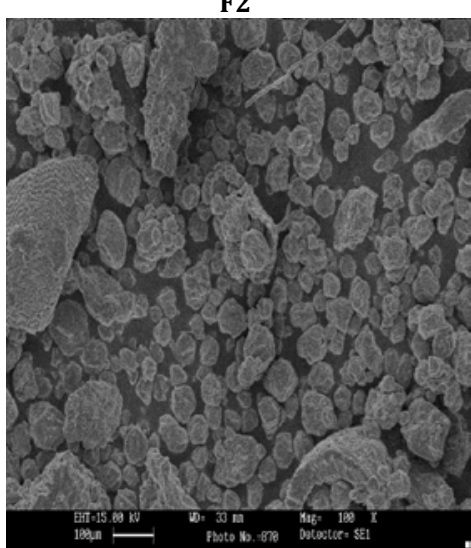

F5

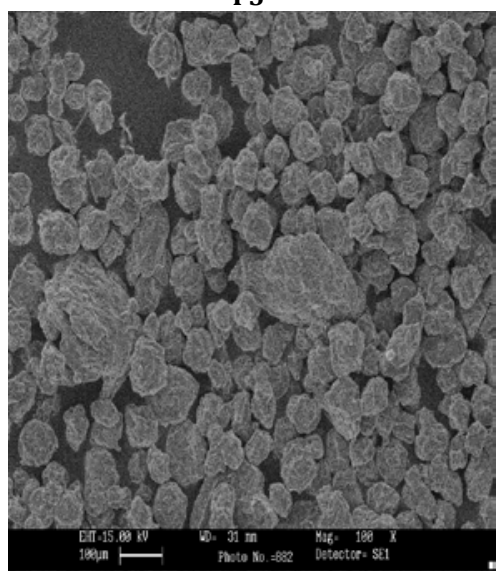

F8
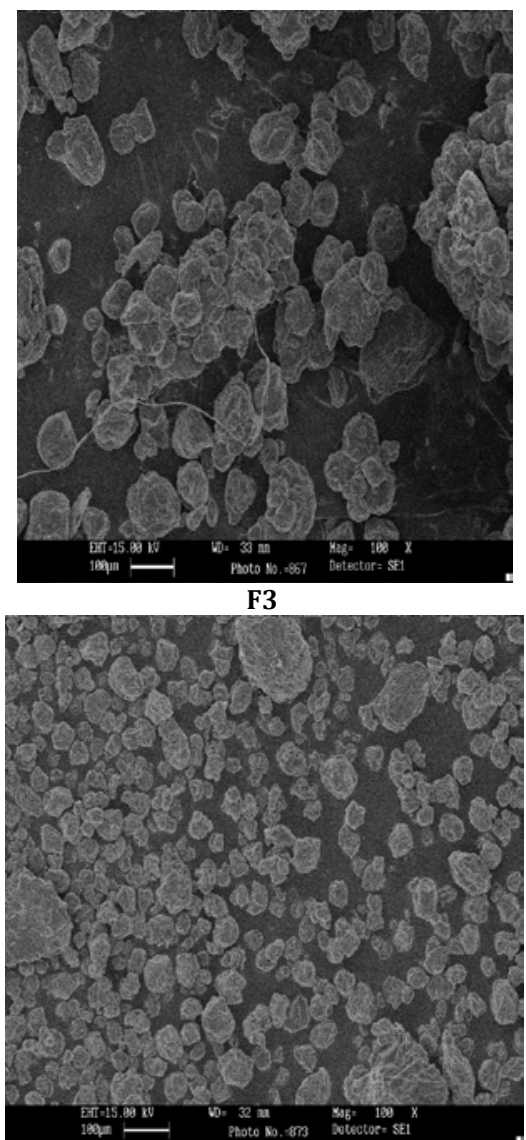

F6

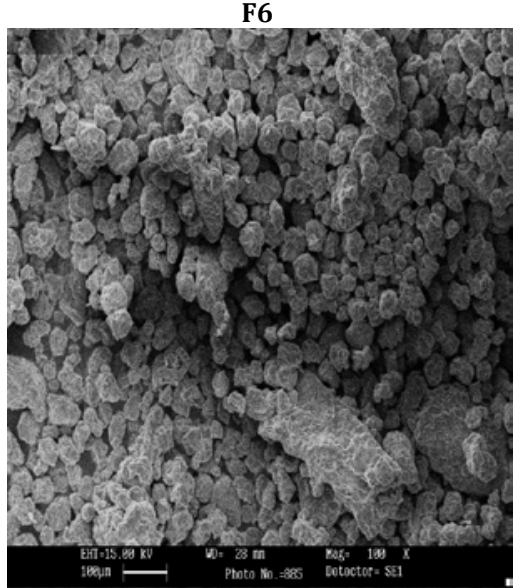

F9

Fig. 4: SEM image all batches at $100 \times$

\section{Result of in vitro drug release}

The release profiles of the drug from different batches of Trigonella foenum-graecum microspheres are shown in fig. 5. Batches of microspheres were found to release $50 \%$ drug within $15 \mathrm{~min}$. , and the whole drug content within $60 \mathrm{~min}$. time except batch F7, which might due to high concentration of Trigonella foenum-graecum polysaccharide retarded the drug release from the microspheres, because of the viscous three-dimensional network at higher concentration of polysaccharide, which reduced the diffusion of drug.

\section{Result of release kinetics}

The release constant was calculated from the slope of the zero order, first order, Higuchi plots and determined the regression coefficient $\left(\mathrm{R}^{2}\right)$ in the range of $0.70-0.98$. It was found that the in vitro drug release of all the nine batches was best explained by zero order kinetic, as plot show the highest linearity, $\mathrm{R}^{2}$ (see table 8), indicating diffusion controlled drug release. The corresponding plot log of cumulative percentage drug release $v s$. log time of the KorsmeyerPeppas equation indicated good linearity of regression coefficient $\left(\mathrm{R}^{2}\right)$; 0.27-0.97. The release exponent $(\mathrm{n})$ values for all the nine 
batches were found to be $>0.45$, indicating that all batches followed the case II transport, which was the drug transport mechanism associated with stress in hydrophilic polysaccharides which swells in water and biological fluids.

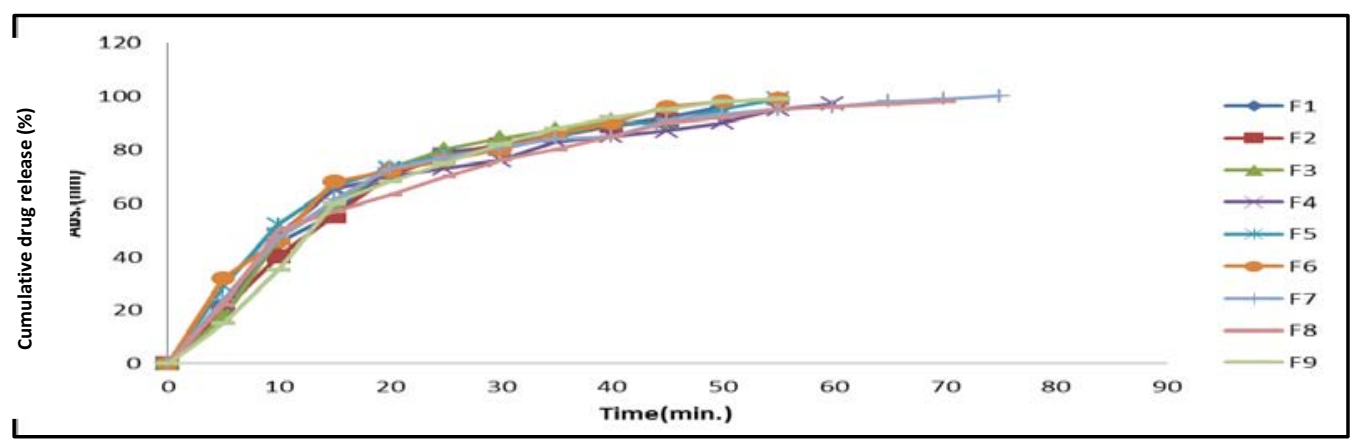

Fig. 5: In vitro release of microspheres. Each reading is an average of six determinants (mean+SD) $(n=6) n=$ no. of observation

Table 8: Model fitting of the release profile using four different models

\begin{tabular}{|c|c|c|c|c|c|c|c|}
\hline \multirow[t]{3}{*}{ Formulations } & \multicolumn{7}{|c|}{ Kinetic models $\left(\mathrm{R}^{2}\right)$} \\
\hline & \multirow[t]{2}{*}{ Zero-order } & \multirow[t]{2}{*}{ First order } & \multirow[t]{2}{*}{ Higuchi } & \multirow[t]{2}{*}{ Best fit model } & \multicolumn{3}{|c|}{ Korsmeyer peppa's equation } \\
\hline & & & & & K value & n value & Mechanism \\
\hline F1 & 0.987 & 0.659 & 0.940 & Zero order & 0.627 & 1.4153 & \\
\hline $\mathrm{F} 2$ & 0.970 & 0.667 & 0.570 & Zero order & 0.9099 & 1.1713 & SupercaseII \\
\hline F3 & 0.701 & 0.995 & 0.977 & Zero order & 0.9713 & 1.1386 & Transport \\
\hline $\mathrm{F} 4$ & 0.928 & 0.521 & 0.860 & Zero order & 0.2796 & 1.7691 & \\
\hline F5 & 0.956 & 0.985 & 0.893 & Zero order & 0.5426 & 1.4305 & \\
\hline F6 & 0.982 & 0.642 & 0.931 & Zero order & 0.6186 & 1.4152 & \\
\hline F7 & 0.962 & 0.802 & 0.916 & Zero order & 0.5138 & 1.3702 & \\
\hline F8 & 0.903 & 0.750 & 0.834 & Zero order & 0.2528 & 1.7623 & \\
\hline F9 & 0.916 & 0.558 & 0.85 & Zero order & 0.2728 & 1.7871 & \\
\hline
\end{tabular}

\section{Stability studies}

Stability studies for the optimized batch (F7) were carried out at a different temperature for $90 \mathrm{~d}$. The formulation was evaluated for physical appearance and entrapment efficiency. There was no significant change in physical appearance and entrapment efficiency even after exposing to stress conditions at a different temperature. Hence, it was concluded that the F7 batch of microspheres has good stability during their shelf life.

\section{CONCLUSION}

The rizatriptan benzoate loaded polysaccharide based microspheres can be successfully prepared by double emulsion techniques. A full $3^{2}$ factorial design was applied taking drug polysaccharide ratio $\left(\mathrm{X}_{1}\right)$ and stirring rate $\left(\mathrm{X}_{2}\right)$ as two independent variables than the dependent variables were evaluated. The prepared batches of microspheres were spherical and free-flowing. The entrapment efficiencies ranged from $60.7+0.2 \%$ to $79.22+0.2 \%$ and mean size was in the range of $40.82+0.12 \mu \mathrm{m}$ to $62.48+0.41 \mu \mathrm{m}$. The concentration of polysaccharide ratio influences the entrapment efficiency. Thus, the investigation indicates a promising potential of control release rizatriptan benzoate loaded microspheres whereas the Trigonella foenum-graecum polysaccharide used as rate controlling polymer for the effective treatment of migraine patients.

\section{AUTHORS CONTRIBUTIONS}

All the authors have contributed equally

\section{CONFLICT OF INTERESTS}

Declare none

\section{REFERENCES}

1. Chandna A, Batra D, Kakar S, Singh R. A review on target drug delivery: magnetic microspheres. Journal of Acute Disease 2013;2:189-95

2. Pathaka R, Dashab RP, Misraa M, Nivs, Arkarb M. Role of mucoadhesive polysaccharides in enhancing delivery of nimodipine microemulsion to brain via intranasal route. Acta Pharm Sin B 2014;4:151-60.

3. Dhakar RC, Maurya SD, Tilak VK, Gupta AK. A review on factors affecting the design of nasal drug delivery system. Int J Drug Delivery 2011;3:194-208.

4. Kadam NR, Suvarna V. Microspheres: a brief review. Asian J Biomed Pharma Sci 2015;5:13-9.

5. Khedkar A, Rajendra V, Kulkarni A, Dehghan MH, Saifee M, Lahoti S. Spectrophotometric method for analysis of rizatriptan benzoate. Int J Pharm Sci 2009;1:307-13.

6. Prasanta S, Padma MS. Estimation of rizatriptan benzoate tablet by using uv spectrophotometric methods. Int J Pharm Sci Res 2013;19:97-100.

7. Basch E, Ulbricht C, Grace K, Pharm D, Philippe S, Smith M. Therapeutic applications of fenugreek. Altern Med Rev 2003;8:20-7.

8. Indian Herbal Pharmacopoeia. Indian drugs manufacturing association Mumbai. Regional Research Laboratory Jammu Tavi 1999;1:33.

9. Suruse PB, Shivhare UD, Mathur VB, Meshram KL, Pathak AD. Development of microcapsules of glimepiride using fenugreek seed extract. Int J Pharm Phytopharmacol Res 2013;3:212-5.

10. Jani GK, Prajapati VD. Gums and mucilage: versatile excipients for pharmaceutical formulations. Asian J Pharm Sci 2009;4:309-23.

11. Sharma N, Kulkarni GT, Sharma A, Bhatnagar A, Kumar N. Natural mucoadhesive microspheres of abelmoschus esculentus polysaccharide as a new carrier for nasal drug delivery. J Microencapsul 2013;30:589-98.

12. Mahajan HS, Tatiya BV, Nerkar PP. Ondansetron loaded pectin based microspheres for nasal administration: in vitro and in vivo studies. Pharm Dev Technol 2012;221:1-9.

13. Kellaway W, Hameed MD. Preparation and in vitro characterization of mucoadhesive polymeric microspheres as intra-nasal delivery systems. Eur J Pharm Biopharm 1997; 44:53-60.

14. Gavini E, Rassu G, Ciarnelli V, Spada G, Cossu M, Giunchedi P. Mucoadhesive drug delivery systems for nose-to-brain targeting of dopamine J. Nanoneurosci 2012;2:47-55. 
15. Rawat A, Majumder $\mathrm{QH}$, Ahsan F. Inhalable large porous microspheres of low molecular weight heparin: in vitro and in vivo evaluation. J Controlled Release 2008;128:224-32.

16. Gavini E, Hegge AB, Rassu G, Sanna V, Testa C, Pirisino G, et al. Nasal administration of carbamazepine using chitosan microspheres: in vitro/in vivo studies. Int J Pharm 2006; 307:9-15.

17. Kar K, Pal RN, Bala NN. Preparation, characterisation, and evaluation of ropinirole hydrochloride loaded controlled release microspheres using solvent evaporation technique. Int J Pharm Pharm Sci 2018;10:57-67.

18. Kumar R, Patil S, Patil MB, Patil SR, Paschapur MS. Isolation and evaluation of disintegrant properties of fenugreek seed mucilage. Int J Pharm Tech Res 2009;1:982-96.
19. Sunder Raj TJ, Bharathi CH, Kumar MS, Prabahar J, Kumar PN, Sharma HK, et al. Identification, isolation, and characterization of process-related impurities in rizatriptan benzoate. J Pharm Biomed Anal 2009;49:156-62.

20. Patil SB, Sawant K. Mucoadhesive chitosan microspheres as a delivery system for nasal insufflation. Colloids Surf B 2011;84:3849.

21. Yang YY, Chung TS, Ng NP. Morphology, drug distribution, and in vitro release profiles of biodegradable polysaccharides microspheres containing protein fabricated by double-emulsion solvent extraction/evaporation method. Biomaterials 2001;22: 231-41.

22. Deshmukh M, Mohite S. Formulation and characterization of olanzapine-loaded mucoadhesive microspheres. Asian J Pharm Clin Res 2017;10:249-55. 